letters to patients (Psychiatric Bulletin, February 2004, 28, 57). My view is that this represents the most intrusive incursion yet by this Government into the central relation between doctor and patient.

My objections to this policy are severa. First, on clinical grounds, I am concerned about the impact of this policy on the welfare of my patients who are children. As a child psychiatrist, one often makes judgements about the nature of attachment relationships and parenting abilities in parents of the children one sees. Frequently, it is in the interests of the child that other health professionals are aware of such difficulties, but not necessarily the parents as this may significantly affect the engagement process.

It seems to me that there are two ways of dealing with the problem of sending copies of letters to patients: one is to leave out information altogether, which I would argue is not in the best interests of the child, and the other is to render the letters so euphemistic as to be meaningless.

Whichever way one chooses to manage this problem, it is clear that we shall be discouraged from the use of medical language: and here we can see the other motivation of the Government in the current political climate, which is to deprofessionalise doctors; in other words, we shall be 'dumbed down'.

The second of my objections is more practical and concerns the enormous administrative burden involved in responding to patients' objections, queries, anxieties and sending out more mail: how is all this to be funded?

At a time when there are still great difficulties in delivering a decent health service to patients, it seems ludicrous that resources are being directed away from direct patient care to attempts at manipulating the public into believing that their health care is being improved by receiving copies of communication from their doctors. Is anyone really going to be fooled by this?

Sarah Huline-Dickens Consultant in Child and Adolescent Psychiatry, Child and Family Consultation Service, Erme House, Mount Gould Hospital, Plymouth PL4 7QD

\section{Mental Health Officer status}

Mears et al (Psychiatric Bulletin, April 2004, 28, 130-132) describe Mental Health Officer status as a 'perverse incentive'. This implies disapproval of the only perquisite ever to have been enjoyed by consultant psychiatrists and other disciplines working in mental health. It may well be that the recruitment into our specialty was enhanced by Mental Health Officer status opportunities, sadly removed, I understand, from new entrants several years ago.

My own Mental Health Officer status was removed without my knowledge when I became an academic. Although it has now been reinstated, the possibility of being obliged to work full-time for an extra 5 years for financial reasons was a most worrying and unattractive one.

However, I am sure that Mears et al have got it right when they say that the reasons why consultants retire early are complex, multidimensional and highly individual. In my own case, the youngest of my three children will only be 12 years old when I am 55, and after having missed out on so much of my children's early years it would be quite nice to spend more time with them when they are older. Like most of the consultants participating in Mears et al's survey, the most attractive prospect is to take early retirement but continue to work parttime in some other capacity. It is difficult to envisage any incentive that could overcome my desire to spend more time with my family, apart from reduced working hours for what is in effect the same pay, which is of course what you end up with by taking early retirement and then working part-time.

Perhaps an investment in allowing older consultants to reduce their hours while maintaining their salary would be worthwhile in terms of both retention of older consultants and in attracting new graduates to our specialty. However I suspect that there are many consultant posts in psychiatry, my own included, which could not be feasible on a parttime basis.

Ann Mortimer Foundation Chair in Psychiatry/ Head of Department, The Postgraduate Medical Institute of the University of Hull (PGMI) in association with the Hull York Medical School, Southcoates Annexe, Cottingham Road, Hull HU6 7RX. E-mail: A.M.Mortimer@hull.ac.uk 